\title{
The Integrated Safety Management System Verification Enhancement Review of the Plutonium Finishing Plant
}

Prepared for the U.S. Department of Energy

Assistant Secretary for Environmental Management

Project Hanford Management Contractor for the

U.S. Department of Energy under Contract DE-AC06-96RL13200

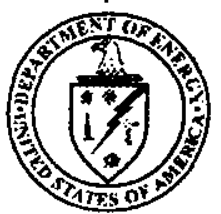

United States Department of Energy

P.O. Box 550

Richland, Washington 99352 


\section{INFORMATION CLEARANCE FORM}

\begin{tabular}{|c|c|}
\hline \multicolumn{2}{|c|}{ A. Information Category } \\
\hline Abstract & $\square$ Journal Article \\
\hline$\square$ Summary & $\square$ Internet \\
\hline$\square$ Visual Aid & $\square$ Software \\
\hline$\square$ Full Paper & $\bigotimes$ Report \\
\hline$\square$ Other & \\
\hline
\end{tabular}

B. Document Number DOE/RL-2000-13, Rew 0
C. Title
The Integrated Safety Management system verification Enhancement
Review of the Plutonium Finishing Plant
\[ \]
D. Internet Address

E. Required Information
1. Is document potentially Classified? ONo OYes (MANDATORY)

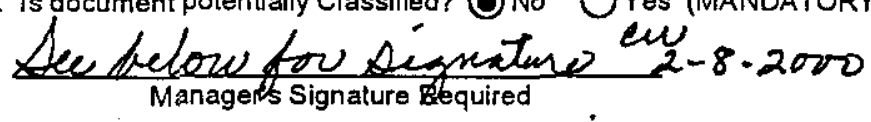

If Yes

ADC Signature Required

2. Internal Review Required?

If Yes, Document Signatures Below

Ono OYes Classified

Counsel

Program

3. References in the Information are Applied Technology

Export Controlled Information
ONo OYes

5

4. Does Information Contain the Following: (MANDATORY)
a. New or Novel (Patentable) Subject Matter?
ONo OYes

If "Yes", Disclosure No.:

b. Information Received in Conlidence, Such as Proprietary and/or Inventions?

ONo OYes If "Yes", Affix Appropriate Legends/Notices.
c. Copyrights? ONo OYes
If "Yes", Attach Permission.
d. Trademarks? ONo OYes
If "Yes", Identify in Document.

5. Is Information requiring submission to OSTI? $O$ No $\bigcirc$ Yes

If Yes UCand $B \& R-$

6. Release Level? $\bigcirc$ Public $\bigcirc$ Limited

7. Charge Code.

F. Complete for a Journal Article

1. Title of Journal

\section{G. Complete for a Presentation}

Integrated Safety management and Public Involuement:

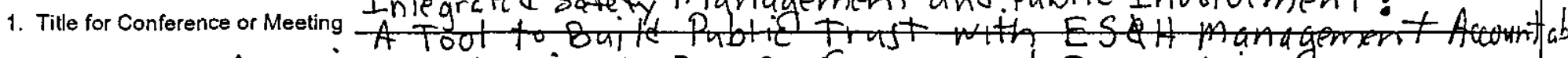

2. Group Sponsoring American Indudrial Hygene conference and Exportion

3. Date of Conference MAY $20-25,2000$ 4. City/state Orland o, Flonida

5. Will Information be Published in Proceedings? ONo OYes oNLY 6. Will Material be Handed Out? No O Yes

H. Author/Requestor

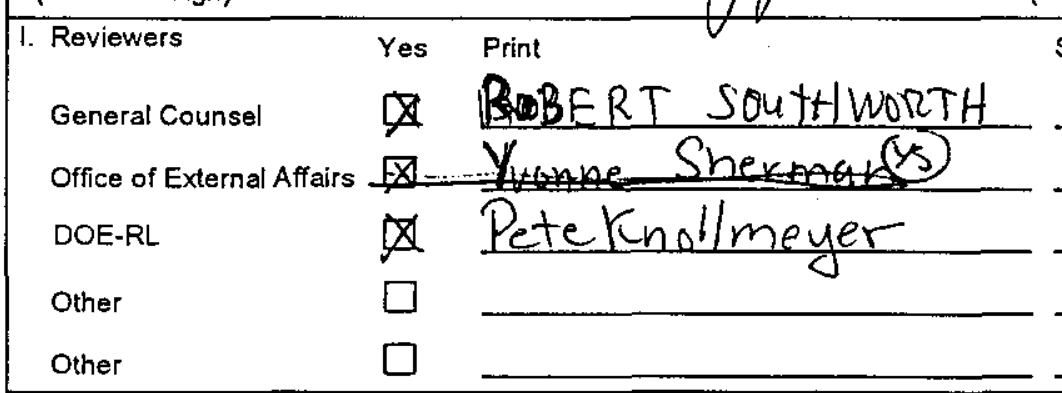

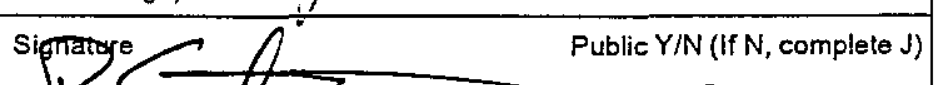

J. If Information Includes Sensitive Information and is not to be released to the Public indicate category below.

$\square$ Applied Technology $\square$ Protecied CRADA

$\square$ Personal/Private $\square$ Export Controlled

$\square$ Proprietary $\square$ Procurement-Sensitive

$\square$ Business-Sensitive $\square$ Patentable

$\square$ Predecisional $\square$ Other (Specify)

$\square$ UCNI

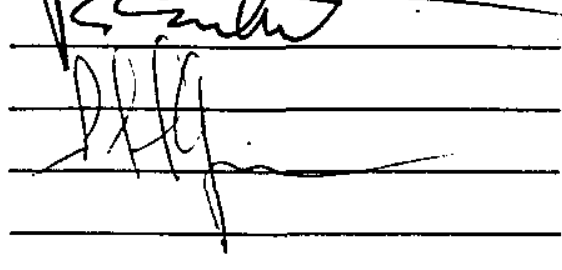

Y $/{ }^{N}$
$Y / N$
$Y / N$
$Y / N$
$Y / N$

K. If Additional Comments, Please Attach Separate Sheet 


\title{
The Integrated Safety Management System Verification Enhancement Review of the Plutonium Finishing Plant
}

\author{
C.R. Briggs
}

U.S. Department of Energy Richland, WA

Date Published

May 2000

Prepared for the U.S. Department of Energy

Assistant Secretary for Environmental Management

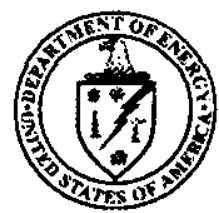

\section{United States}

Department of Energy

P.O. Box 550

Richland, Washington 99352 


\section{TRADEMARK DISCLAIMER}

Reference herein to any specific commercial product, process, or service by trade name, trademark, manufacturer, or

otherwise, does not necessarily constitute or imply its

endorsement, recommendation, or favoring by the United

States Government or any agency thereof or its contractors or subcontractors.

This report has been reproduced from the best avallable copy. Available in paper copy and microfiche.

Available electronically at http://www.doe.gov/bridge. Available for a processing fee to the U.S. Department of Energy and its contractors, in paper, from:

U.S. Department of Energy

Office of Scientific and Technical Information

P.O. Box 62

Oak Ridge, TN 37831-0062

phone: $865-576-8401$

fax: 865-576-5728

email: reports @adonis.osti.gov(423) 576-8401 


\section{The Integrated Safety Management System Verification Enhancement Review of the Plutonium Finishing Plant}

Report prepared by:

- Roger Briggs - Department of Energy, Richland Operations Office

- Lori Ramonas - Nuvotec, Inc.

- Joe Escamillo - Department of Energy, Richland Operations Office

- Mike Stoner - Fluor Hanford, Inc.

- Doug Huston - Oregon Office of Energy 


\section{ACKNOWLEDGEMENTS}

Review Team leads, Roger Briggs and Lori Ramonas, would like to thank the following individuals without whose help this project would not have been possible:

- Pete Knollmeyer, Assistant Manager for Nuclear Materials and Facility Stabilization, RL, for his personal sponsorship of the project;

- Paul Kruger, former Director of Environment, Safety, and Health, RL, for his long-term commitment to adapt best ESH practices from the private sector and for his personal support of the project; and,

- Review Team members Mike Stoner, Joe Escamillo, and Doug Huston for their energy, insight, and time commitment to participate in the project. 


\section{TABLE OF CONTENTS}

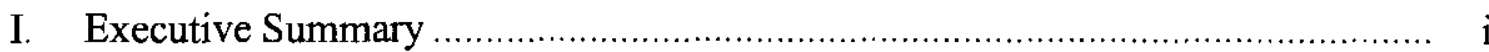

II. Purpose of the Enhancement Review .......................................................... 1

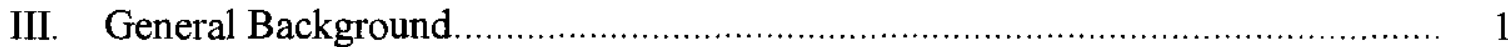

A. The MSV@ Process ............................................................................... 1

B. DOE Involvement with ESH "Best Practices" of the Chemical Industry .......... 2

IV. Methodology for the ISM Verification Enhancement Review ............................. 4

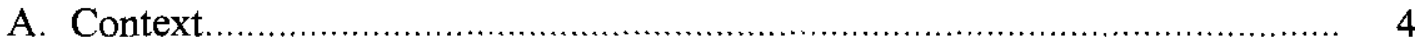

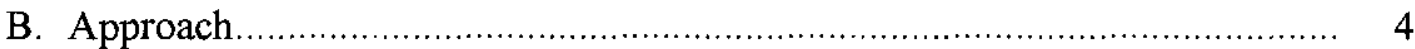

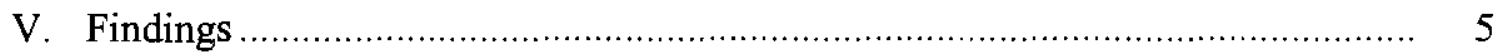

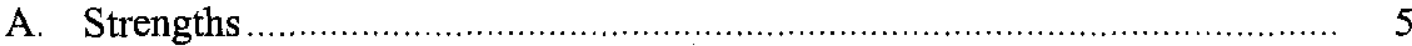

B. Opportunities for Improvement ……................................................... 7

VI. Evaluation of the Effectiveness of the Enhancement Review …........................... 8

VII. Lessons Learned...................................................................................... 10

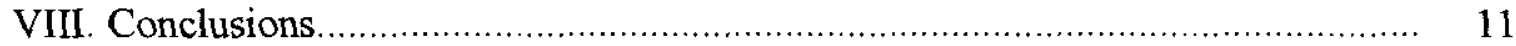

Appendix A - An Overview of the Responsible Care ${ }^{\circledR}$ Initiative ..................................... 13

Appendix B-A Comparison of Phase II Integrated Safety Management System

Verification (ISMSV) Criteria with Responsible Care ${ }^{\circledR}$ Management

System Verification $(M S V){ }^{\circledR}$ Attributes ...................................................... 15

Appendix C-Panel Participants for the PFP ISMS Verification Enhancement Review . 29

Appendix D - Interview Questions for the Enhancement Review ............................. 30

Appendix E-Enhancement Review Effectiveness Survey ......................................... 34

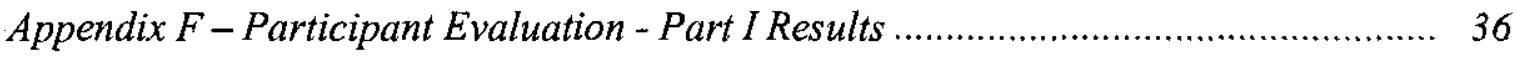

Appendix G - Participant Evaluation - Part II Results ........................................... 40 


\section{EXECUTIVE SUMMARY}

The primary purpose of the verification enhancement review was for the DOE Richland Operations Office (RL) to verify contractor readiness for the independent DOE Integrated Safety Management System Verification (ISMSV) on the Plutonium Finishing Plant (PFP). Secondary objectives included: 1) to reinforce the engagement of management and to gauge management commitment and accountability; 2) to evaluate the "value added" benefit of direct public involvement; 3) to evaluate the "value added" benefit of direct worker involvement; 4) to evaluate the "value added" benefit of the panel-to-panel review approach; and, 5) to evaluate the utility of the review's methodology/adaptability to periodic assessments of ISM status.

The enhancement review was modeled after the Chemical Manufacturers Association's (CMA) Management Systems Verification (MSV) ${ }^{\circledR}$ process. The MSV ${ }^{\circledR}$ process, which was developed by CMA's member chemical companies specifically as a tool to assist in the continuous improvement of environment, safety, and health (ESH) performance, represents a commercial sector "best practice" for evaluating ESH management systems.

The review was conducted on December 6-8, 1999, and involved the conduct of two-hour interviews with five separate panels of individuals with various management and operations responsibilities related to PFP. A semi-structured interview process was employed by a team of five "reviewers" who directed open-ended questions to the panels which focused on: 1) evidence of management commitment, accountability, and involvement; and, 2) consideration and demonstration of stakeholder (including worker) information and involvement opportunities.

The purpose of a panel-to-panel dialogue approach was to better spotlight: (1) areas of mutual reinforcement and alignment that could serve as good examples of the management commitment and accountability aspects of ISMS implementation; and, (2) areas of potential discrepancy that could provide opportunities for improvement.

The Review Team was comprised of the following individuals: 1) Lori Ramonas (Nuvotec) / Facilitator; 2) Roger Briggs (RL) / ESH Program Representative; 3) Joe Escamillo (RL) / Line Management Representative from the Office of Spent Nuclear Fuels; 4) Michael Stoner (FDH) / HAMTC Health and Safety Representative; and, 5) Doug Huston (Oregon Office of Energy) / Public Participant.

In summary, the Review Team found major strengths to include: 1) the use of multi-disciplinary project work teams to plan and do work; 2) the availability and broad usage of multiple tools to help with planning and integrating work; 3) senior management presence and accessibility; 4) the institutionalization of worker involvement; 5) encouragement of self-reporting and self-assessment by management; 6) the availability of multiple internal communication mechanisms; and, 7) the existence of overall facility-wide safety management goals as well as individualized project work team goals. Major opportunities for improvement identified include: 1) the enhancement of external communications relative to ISM; 2) the institutionalization of ISM-related performance agreements/incentives; 3 ) the strengthening of feedback loops; 4) fine-tuning the use of tools; and, 5 ) the formalization of good practices. The findings of the Review Team are discussed in more detail in Section V. 
An "Effectiveness Survey" was completed by each panel participant immediately following the two-hour interview. The results of the Effectiveness Survey indicated that enhancement review was very effective in general and especially effective for evaluating the overall sustainability of ISM.

The Review Team concluded that the enhancement review process was an effective and expeditious mechanism for gaining insightful information into the implementation and long-term sustainability of the ISM safety culture at PFP. Furthermore, the Review Team recommended that, at a minimum, this review process be conducted on a different facility, also scheduled for a DOE ISMS verification, in the near future. 


\section{PURPOSE of ENHANCEMENT REVIEW}

The overall purpose of the ISMS Verification Enhancement Review was to examine the potential "value added" aspects of the chemical manufacturing industry's "best practice" approach for evaluating ESH management systems, called MSV ${ }^{\circledR}$, for application to DOE's ISMS verification efforts. As such, this review effort focused on the PFP Facility at Hanford which was scheduled to undergo an independent DOE ISMS Verification a few weeks following the completion of the review. The primary specific purpose of the review was to serve as RL's verification of contractor readiness for the upcoming DOE ISMS verification. The review emphasized Guiding Principles \#8, \#9, and \#11 from the ISMS Program Description of PFP which address: 1) evidence of management commitment, accountability, and involvement; and, 2) demonstration of stakeholder (including worker) information and involvement. Secondary purposes for the review included: 1) to reinforce the engagement of management and to gauge management commitment and accountability; 2) to evaluate the "value added" benefit of direct public involvement; 3) to evaluate the "value added" benefit of direct worker involvement; 4) to evaluate the "value added" benefit of the panel-to-panel review approach; and, 5) to evaluate the utility of the review's methodology/adaptability to periodic assessments of ISM status.

\section{GENERAL BACKGROUND}

\section{A. The MSV@ Process}

The enhancement review was modeled after the Chemical Manufacturers Association's (CMA) Management Systems Verification (MSV) ${ }^{\circledR}$ process. To understand the context of the MSV@ process, it is necessary to understand the overall framework into which it fits, Responsible Care ${ }^{\oplus}$. Responsible Care ${ }^{\oplus}$ is an initiative of the U.S. chemical manufacturing industry. It was launched in 1988 by CMA as an industry-wide response to escalating public concerns about ESH practices of the chemical industry following the Bhopal accident in December, 1984. The CMA is a non-profit trade association whose approximately 195 member companies account for more than 90 percent of basic industrial chemical production in the United States. The focus of Responsible Care ${ }^{\oplus}$ is to continually improve the performance of the chemical industry in the areas of ESH stewardship and to be responsive to public concerns about the industry's overall management of chemicals. Additional background information on Responsible Care ${ }^{\circledR}$ can be found in APPENDIXA.

The Responsible Care ${ }^{\circledR}$ MSV ${ }^{\oplus}$ process is built around a verification protocol or guidance document which organizes the verification into a general sequence of steps which examine five core areas: 1) Policy and Leadership; 2) Planning; 3) Implementation, Operation, and Accountability; 4) Performance Measurement and Corrective Action; and 5) Management Review and Reporting. These core areas are identical to the five identified for ISO 14000 and also incorporate the five core functions of ISM. 
Sub-divided within the five core areas CMA delineates 35 "attributes". These "attributes" are the necessary systems, organizations, policies, programs, etc., that support each core area of the management system and are the basis for the evaluation of the overall management system. Evidence of the existence of these attributes and their integration into the company's operations and culture are the focus of the MSV® process.

The 35 attributes of the MSV® process were compared to the Phase II CRADs for ISM Verification. The results of this comparison are illustrated in $A P P E N D I X B$. In essence the attributes and CRADs frequently matched with respect t $\mathrm{s}$ the following areas: 1) systems for assessing hazards and risks; 2) review of contractor performance; 3) analysis of trends and performance; 4) training; 5) processes for reviewing regulations; 6) documentation of procedures; and, 7) establishment of goals, objectives, and targets. There was less frequent match of CRADs to the MSV® attribute areas of: 1) policy and leadership; and, 2) management review and reporting. Finally, specific MSV® attribute areas addressing stakeholder and public involvement were absent in the CRADs.

In the Responsible Care ${ }^{\oplus}$ MSV$^{\oplus}$ process, industry peers, with experience in management systems, accompanied by community representatives, first conduct a disciplined and comprehensive review of the necessary documentation (policies, programs, procedures) which forms the underlying foundation of the ESH management system. Then the industry peers and community representatives engage in a series of open-ended interviews with company personnel to determine whether a company indeed has appropriate, functioning and sustainable management systems in place. Through this combined documentation review and panel interview observation process, the industry peers and community representatives are able to identify strengths and areas for improvement in the company's management systems. These findings are submitted to the company being verified in a final written report.

It is important to note that the MSV® process does NOT replace the more traditional audit/self-assessment practices that continue in place at most chemical facilities, rather it complements them.

\section{B. DOE Involvement with ESH "Best Practices" of the Chemical Industry}

In February 1994, Secretary O'Leary initiated a vulnerability review of chemical safety at DOE sites. The review, which was completed in July 1994 and involved the evaluation of 146 facilities at 29 sites across the DOE complex, identified eight generic vulnerabilities, and generic management weaknesses in five programmatic areas. To address these findings a management response plan was developed by the Assistant Secretary for Environment, Safety and Health and endorsed by all of the Department's Cognizant Officers. The response plan highlighted industry partnerships as key to improving safety at DOE sites and specifically referenced Responsible Care ${ }^{\circledR}$ as an exemplary industry initiative in chemical safety. 
Since 1994, applying chemical industry best practices for chemical safety to DOE sites has been part of an ongoing, focused effort by DOE's Office of the Deputy Assistant Secretary for Worker Health and Safety (EH-5). This effort was formalized in an August 1996 Memorandum of Understanding between DOE and the CMA which encourages the sharing of exemplary policies, procedures and practices for continuous improvement in ESH.

The Hanford Site has had a long standing involvement with chemical industry networking and bench-marking in the area of ESH continuous improvement. Recent examples include:

1. Participation in conference calls with Ashland Chemical Company (Fall, 1996) on the development, implementation and evaluation of integrated ESH management systems;

2. Sponsorship of a Rohm \& Haas Company visit to the site (Spring, 1997) to examine the application of chemical industry best practices in integrated ESH management systems to the site's evolving ISMS effort;

3. Incorporation of key Responsible Care ${ }^{\oplus}$-related guiding principles on "management commitment" and "community involvement/outreach" into the site's final ISMS framework (Fall, 1997); and,

4. Development of a state-of-the-art Chemical Management System (CMS) framework for the site based on benchmarking with and assistance from the DuPont Chemical Company (Spring 1998).

In late spring of 1998 , the Hanford Site conducted a pilot to test the applicability and utility of the MSV ${ }^{\circledR}$ process in the DOE environment using the Project Hanford Management Contractor's CMS as the "test program." The CMS/MSV ${ }^{\circledR}$ pilot was judged extremely successful by both the review/verifier team and, most important, by panel participants. The conclusion drawn from that pilot was that an MSV $^{\circledR}$-like process could have significant value added as a "front end" process in conjunction with internal preparation for an ISMSV. (For a complete copy of the July 24, 1998, "Evaluation of the Management Systems Verification Pilot at Hanford," reference DOE document number DOE/RL-98-80, Revision 0 or access at web site address www.hanford.gov/docs $/ \mathrm{rl}-98-80 / \mathrm{rl}-98-80 . \mathrm{html}$ ).

The ISMS Verification Enhancement review of PFP, therefore, represents a continuum of Hanford's pioneering efforts to adapt chemical industry ESH practices, where relevant and applicable, to the site's operations, including the implementation of ISM. 


\section{METHODOLOGY FOR THE ISM VERIFICATION ENHANCEMENT REVIEW}

\section{A. Context}

On September 15, 1999, a contractor readiness review was conducted (of which RL participated only in an ex-officio capacity) which focused on evaluating the implementation of Phase I and II CRADs at the PFP facility. Therefore, since the primary objective of the ISM Verification Enhancement Review was to serve as RL's verification of contractor readiness for the January 2000 DOE ISMS verification, this review focused on evaluating those areas where there was less frequent or no match of ISMS Phase II CRADs to MSV $₫$ attributes, namely: 1) policy and lead:rship; 2) management review and reporting; and, 3) stakeholder and public involvement (refer to Appendix B). As such, the full range of MSV -type questions, such as those relating to hazard and risk assessment systems, analysis of trends and performance, review of regulations, documentation of procedures, etc., deliberately was NOT covered in a concerted effort to avoid duplicating the content of the previously mentioned September $15^{\text {th }}$ review.

THE ENHANCEMENT REVIEW, WHILE MODELED AFTER CMA'S MSV@ PROCESS, INCORPORATED A UNIQUE FEATURE THAT CURRENTLY IS NOT A REQUIREMENT OF MSV@, NAMELY THE DIRECT PARTICIPATION OF A WORKER AS A MEMBER OF THE REVIEW TEAM.

\section{B. Approach}

The overall approach for the conduct of the pilot was to follow the MSV® protocol as much as practicable. As such, Review Team leads, Roger Briggs, DOE-RL and Lori Ramonas, Nuvotec, Inc., first reviewed relevant PFP documentation contained in the September 15, 1999, PFP ISMS Phase I/II Readiness Review - Senior Management Review Board Presentation which included a PFP ISM program description and detailed evaluations, including strengths, opportunities for improvement, and recommendations, for each Phase I and Phase II CRAD. The full five-member Review Team then interviewed five panels (three to six members each) of "functional teams" within DOE-RL, PFP, and FDH who were directly involved with PFP management and/or operations to determine how various ISMrelated policies, procedures and practices were being implemented. Each panel interview took two hours. Panel participants and their affiliation are listed in APPENDIXC.

The Review Team leads, Roger Briggs and Lori Ramonas, had significant collective experience in: 1) management systems development and implementation (one lead was directly involved in the development of Responsible Care ${ }^{\oplus}$, the ESH management system for the U.S. chemical manufacturing industry; 2) MSV® (both leads underwent CMAsponsored MSV® training); and, 3) relevant ESH commercial and government practices (one lead was a certified industrial hygienist with DOE ESH experience). Other Review Team members had significant Hanford familiarity and experience, specific PFP experience, program management knowledge, and/or general nuclear facility familiarization. 
Questions were asked by the Review Team to engage and facilitate discussion on ISM implementation relative to the PFP facility. All panelists were given ahead of time the list of questions, included in $A P P E N D I X D$, that the interviewers used as a guide to facilitate the semi-structured interview process.

Although the interview process focused questions on management at a systems level for each panel, the process was "tailored," before and during the interview, to allow panelists the opportunity to focus on those areas of greatest personal interest, energy and impact to them.

Finally, an Effectiveness Survey, included in APPENDIX E, was administered immediately following panel discussion in order to: 1) guarantee $100 \%$ response by participants; and, 2) capture panelists' first thoughts and impressions following the completion of the verification enhancement review.

\section{FINDINGS}

The identification of specific strengths and opportunities for improvement resulted from a systematic distillation of panelists' comments in response to questions asked during the two hour panel-to-panel dialogue process. Comments that were made by several panelists, reinforced one another, and highlighted accomplishments relative to ISM implementation, were noted as strengths. Comments that indicated differences in the understanding and/or application of policies, procedures and/or practices relative to ISM, or that indicated a lack of management system performance relative to ISM implementation, were noted as opportunities for improvement.

\section{A. $\underline{\text { STRENGTHS }}$}

1.0 Facility Representatives are viewed by PFP employees and contractor management as credible and as an effective and approachable "line of contact" for employees with ESH-related issues.

(Facility Representatives were viewed as very constructive by all panelists and, in the opinion of the Review Team, represented an effective and well functioning "feedback loop".)

2.0 Multiple tools (i.e., Automated Job Hazard Analysis [AJHA], Employee Job Task Analysis [EJTA], Integrated Project Management Plan [IPMP], Plan of the Day/Week/Month, etc.) are available and broadly used throughout PFP for planning and integrating work and for determining resource and training needs associated with that work. 
(PFP management and staff were noticeably proud to be the first Hanford facility to have implemented the AJHA process throughout the facility.)

3.0 Self-reporting and self-assessment (i.e., safety log books, facility safety committees, As Low As Reasonably Achievable [ALARA] Council, President's Zero Accident Committee $[P Z A C]$, etc.) are encouraged by management. Success is defined by how quickly and effectively ESH issues and concerns are resolved and NOT by a decrease in the number of reports made.

4.0 Worker involvement (i.e., ISM Workshop attendance by bargaining unit representatives, ISM training for workers, etc.) is supported by management, integrated, and institutionalized as a way of doing business. ISM significantly assisted in solidifying this practice throughout PFP.

5.0 Multiple internal communication mechanisms (i.e., Hanford Reach, PZAC, ALARA Council, Plan of the Day/Week/Month, etc.) are available to provide ESH-related information to all employees and to allow for employee input and feedback.

6.0 Project work teams are institutionalized throughout PFP. These multi-disciplinary, integrated teams plan work, do work, establish ESH goals related to the work, etc. and are a visible demonstration and reinforcement of the principals of ISM in practice.

(While the project work team approach had been implemented only two months at the time of this review, these teams already had visible impact on work planning and implementation processes.)

7.0 The PZAC and the ALARA Council have roles in helping to establish overall facility-wide safety management goals. However, individual project teams are encouraged to "tailor" those goals and set "stretch" goals for themselves thereby allowing for more direct "ownership" by the project teams.

8.0 Management presence (i.e., facility walk-arounds, Senior Supervisory Watch) "on the shop floor" and management accessibility (i.e., open door policies) are both visible indicators of management's commitment to ISM.

(While top management and first-line supervisors were viewed as present and accessible by panelists, middle management in general was not viewed as favorably with respect to these areas.) 


\section{B. OPPORTUNITIES for IMPROVEMENT}

1.0 There is tremendous opportunity to significantly improve external communications and stakeholder involvement efforts associated with ISM. Such efforts would have the potential to build public trust and credibility by significantly enhancing a broader understanding of the safety culture at PFP.

(While the Review Team recognizes that public/stakeholder communications and involvement are not required by ISM CRADs, nonetheless it was the opinion of the Review Team that some institutional-level efforts directed along these lines could have tremendous positive impact and, therefore, warranted serious consideration.)

2.0 The implementation of ISM should be continuously fine-tuned by ensuring that tools such as the AJHA, EJTA, etc., are properly used (neither overused nor underused) and do not unintentionally, over time, begin to substitute for a true understanding of ISM's fundamental principles.

3.0 Institutionalize an RL / contractor negotiation process that focuses on developing performance agreements / incentives that help ensure the continued implementation and long-term sustainability of ISM.

(Based on the differing comments of panelists, it was unclear to the Review Team as to whether there were or were not performance incentives in place to help institutionalize ISM. If indeed there exist such incentives, those incentives need to be better communicated and understood throughout all levels of PFP management and staff. On the other hand, if such incentives do not exist, the consideration of developing them is warranted.)

4.0 Strengthen feedback loops (i.e., post-job review process) so that ISM can sustain continuous improvement over time.

(Although the post-job review process was repeatedly referred to as needing improvement, the opinion of the Review Team was that ISM feedback loops in general needed strengthening.)

5.0 There is an opportunity to formalize good practices (i.e., Team Handbooks) more uniformly by institutionalizing processes that promote and reward the development, implementation, and sharing of good practices throughout PFP. In this manner good practices become a way of doing business and are not dependent upon individual managers, employees and/or organizations for their promotion. 


\section{EVALUATION OF THE EFFECTIVENESS OF THE ENHANCEMENT REVIEW}

The effectiveness of the review process was gauged from the quantitative and qualitative responses provided by panel participants in response to the Effectiveness Survey.

\section{A. Participant Evaluation Surveys}

The Effectiveness Survey attempted to capture both quantitative (Part I) and qualitative (Part II) impressions of the review process from panel participants. In Part I, panelists were asked to rate the effectiveness of the review process' panel-to-panel dialogue approach, on a scale of 1 to 5 , in addressing 10 key areas of management system performance related to the ISM. The effectiveness rating scale was qualified as ranging from "not at all effective" (1) to "extremely effective" (5). The summary results indicated that each of the 10 identified areas received, on average, at least a "passing" or "acceptable" rating of 3.0 or greater. The following areas received a significantly higher $(>3.75)$ eff sctiveness rating:

1. Establishment of clear roles and responsibilities

(Average rating: 3.84)

2. Senior management direction and leadership

(Average rating: 3.84)

3. Relevance of goals and objectives

(Average rating: 3.94)

4. Individual worker/employee accountability

(Average rating: 3.89)

5. Internal communications of policies and activities

(Average rating: 3.84)

6. Overall sustainability of ISM

(Average rating: 4.05)

MOST NOTABLE IS THAT "OVERALL SUSTAINABILITY OF ISM" RECEIVED THE HIGHEST EFFECTIVENESS RATING OF ALL 10 AREAS. A complete display of the quantitative results from Part I, illustrating the range of responses between and within various panels, can be found in $A P P E N D I X F$.

In Part II, panelists were asked to provide qualitative, narrative responses to five questions. The summary results, per individual question, are as follows: 
1. Did this review help to gauge overall management commitment related to the ISM? Please explain.

\section{(17-yes, 1-no, 1-undecided)}

The vast majority of panelists felt that questions relating to management commitment were germane, stimulated good thought, and spotlighted management commitment to ISM as a necessary top priority.

2. Was there value to having a worker as part of the review team? Please explain.

(19-yes)

There was universal and enthusiastic panelist support for having a worker participate as part of the Review Team. Panelists believed that since the worker is key for safety and for the implementation of ISM, direct worker involvement in the ISM review process helps to make the review more credible while also keeping it relevant, practical, and anchored on truly understanding how well ISM is applied in the field where it really matters.

3. Was there value to having a member of the public as part of the review team? Please explain.

\section{(14-yes, 1-no, 4-undecided)}

Unfortunately, the public participant was unable to participate in one of the panelto-panel dialogue sessions and the impact of his absence is reflected in the higher number of "undecided" responses to this question. The majority of panelists, however, indicated that direct public involvement as part of the review process was valuable, helped to provide a good perspective of external views, and also helped to add credibility to the review process. 
4. Was there value to having a panel-to-panel dialogue versus a one-on-one discussion and/or presentation followed by questions? Please explain.

\section{(18-yes, 1-no)}

The vast majority of panelists believed that the panel-to-panel dialogue approach was less intimidating, triggered relevant discussion that might not have occurred otherwise, improved the depth of responses, and was more conducive to frank dialogue because of its interactive nature.

5. Do you see any value for this type of a review to provide a periodic assessment of ISM status?

\section{(17-yes, 2-no)}

Again, a vast majority of panelists felt that the verification enhancement review was expedient AND effective, forced the organization being reviewed to look both inward and outward with respect to ISM, and, if used as a periodic review of ISM, would help to keep ISM momentum going.

\section{Other comments?}

The five individuals who chose to respond to this question indicated that while overall the panel review process was a good experience and useful, they cautioned that it should be used in conjunction with other examples of performance and that while people need to be held accountable, the bureaucracy for doing that needs to be kept simple.

\section{LESSONS LEARNED}

The Review Team, upon completion of the enhancement review process, offered several observations and recommendations for improving the process in the future.

\section{WORKER PANEL}

The worker panel(s) needs to be more carefully constructed in the future. Labor, in addition to management, should be consulted ahead of time to ensure that a well- 
balanced worker panel(s) is assembled that represents a broad range of views. Also worker panel members need to receive adequate notification and understanding of management's expectations regarding their participation in the process.

\section{WORKER QUESTIONS}

Questions for the worker panel(s) should be more specific to the work of the representatives on the panel(s) and have less emphasis on global and/or managementrelated topics.

\section{GENERAL PANEL COMPOSITION}

Care needs to be taken to ensure that panels do not have supervisors and subordinates represented on the same panel in order to better promote an environment that fosters open discussion and a free exchange of thoughts and ideas.

\section{ORGANIZATIONAL CHANGE}

While this review process is ideally intended to evaluate a mature and stable system, it worked successfully with the PFP facility even though major PFP re-organization efforts had not had sufficient time to stabilize and several of PFP's ISM safety culturerelated processes had not had sufficient time to be institutionalized.

\section{RECOMMENDATION FOR IMMEDIATE FUTURE}

This review process was an effective mechanism for gaining insightful information into the implementation and long-term sustainability of the ISM safety culture at PFP. Another review should be done in the near future on a different facility, also scheduled for a DOE ISMS verification, whereby a "full range" of safety-related management system questions could be discussed.

\section{CONCLUSIONS}

The conclusions that can be drawn from this verification enhancement review are definitive and are as follows:

1. The primary specific purpose for conducting the review was accomplished: The review was successful as an RL verification of contractor readiness to undergo a DOE ISMS verification.

This success is evidenced by the overwhelmingly positive responses of Panel A, the RL Upper Management Panel, to the five narrative questions in Part II of the Effectiveness Survey (refer to Appendix $G$ ). Success was further evidenced in a post-enhancement 
review de-briefing with Pete Knollmeyer, sponsor of the project, and his senior staff in which the findings were previewed. The general sense of the group was that the review provided useful information with respect to contractor readiness and, the inclusion of a worker as part of the Review Team, was instrumental for both the success and credibility of the effort.

2. The five secondary purposes of the review also were accomplished since the review successfully: a) reinforced management engagement and gauged management commitment and accountability; b) provided "value added" benefit because of direct public involvement; c) provided "value added" benefit because of direct worker involvement; d) provided "value added" benefit because of the panel-to-panel dialogue approach which is integral to the conduct of the process; and, e) demonstrated its utility as a potential method for effectively and expeditiously providing a periodic assessment of ISM status.

The above mentioned successes are all evidenced by the decidedly positive responses of panel participants to the five narrative questions in Part II of the Effectiveness Survey (refer to Appendix $G$ ).

3. Based on the solid proven success of this enhancement review, THE FINAL RECOMMENDATIONS OF THE REVIEW TEAM ARE:

- CONDUCT ADDITIONAL ISM VERIFICATION ENHANCEMENT REVIEWS AT HANFORD, TARGETING THOSE FACILITIES ALSO SCHEDULED FOR DOE ISMS VERIFICATION, WHEREBY A "FULL RANGE" OF SAFETY-RELATED MANAGEMENT SYSTEM QUESTIONS COULD BE DISCUSSED; AND,

- PROMOTE THE USE OF THE ISM VERIFICATION ENHANCEMENT REVIEW PROCESS AT HANFORD, AND THROUGHOUT THE DOE COMPLEX, AS AN EFFECTIVE AND EXPEDITIOUS PROCESS FOR PERIODICALLY EVALUATING THE STATUS OF ISM IMPLEMENTATION OVER TIME. 


\section{AN OVERVIEW of the RESPONSIBLE CARE ${ }^{\circledR}$ INITIATIVE}

There are 10 primary elements of CMA's Responsible Care ${ }^{\circledR}$ which include:

1. GUIDING PRINCIPLES - Statements of philosophy and commitment regarding health, safety and environmental responsibilities in the management of chemicals. CMA member companies pledge to manage their businesses according to these principles.

2. CODES OF MANAGEMENT PRACTICES - The heart of Responsible Care ${ }^{\circledR}$ initiative is the six codes which address state-of-the-art "best practices" in specific areas of chemical manufacturing, transporting and handling that companies make continuous good-faith efforts to attain. The six codes are (in order of their development and subsequent approval): a) Community Awareness and Emergency Response; b) Pollution Prevention; c) Process Safety; d) Distribution; e) Employee Health and Safety; and, f) Product Stewardship.

3. PUBLIC ADVISORY PANEL - A group of health, safety and environmental thought leaders which assists the industry in identifying and developing programs and actions that are responsive to public concerns.

4. MEMBER SELF-EVALUATIONS - Self-evaluations are reported annually to CMA by each member company on each code. The self-evaluations are a valuable management tool which provide a measure of individual member company progress and help CMA appropriately direct mutual assistance efforts.

5. MEASURES OF PERFORMANCE - Tangible performance measures have been developed for each code to help the industry and the public better understand the progress being made under Responsible Care ${ }^{\oplus}$.

6. MANAGEMENT SYSTEMS VERIFICATION ${ }^{* * *}$ - An MSV® process has recently been developed, which includes appropriate public involvement, to assist member companies with ESH performance improvement.

7. EXECUTIVE LEADERSHIP GROUPS - Industry executives meet regularly to share experiences, review progress and identify areas where assistance is needed. This forum is an important "peer pressure" mechanism for maintaining momentum and commitment by industry senior management 
8. MUTUAL ASSISTANCE - Member companies must help one another in implementing all aspects of Responsible Care ${ }^{\Theta}$. Mutual assistance focuses on direct networking at executive, management and practitioner levels.

9. PARTNERSHIP PROGRAM - This program provides an opportunity for non-CMA companies to become involved in the Responsible Care ${ }^{\circledR}$ initiative.

10. OBLIGATION OF MEMBERSHIP - Bylaws obligate CMA member companies to participate in all elements of the Responsible $\mathrm{Care}^{\circledR}$ initiative. 


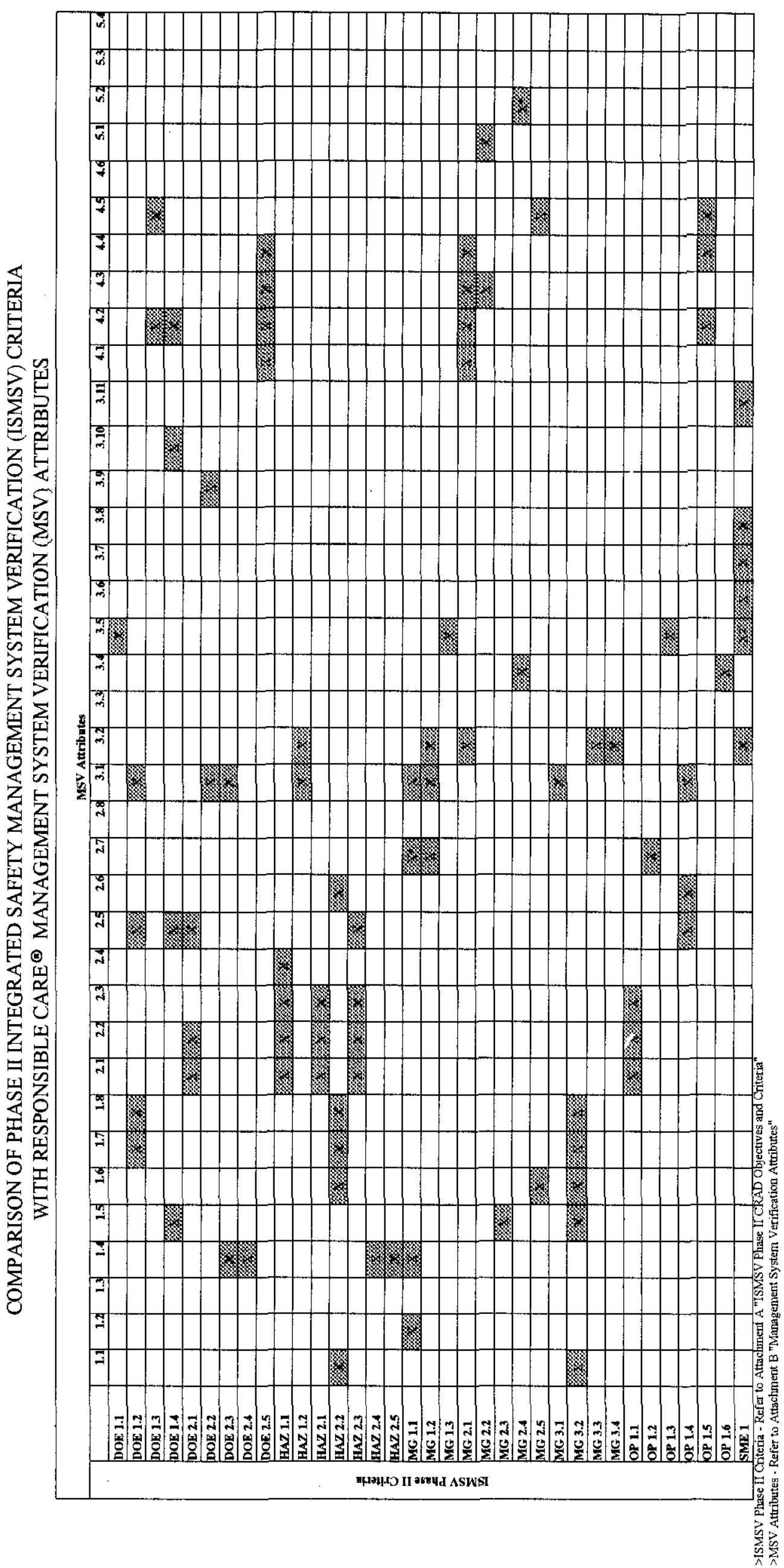




\section{OVERVIEW SUMMARY of MATCH \\ of ISMSV PHASE II \\ CRITERIA with MSV๑ ATTRIBUTES}

\section{A. MOST FREQUENTLY MATCHED MSV๑ ATTRIBUTES TO ISMSV CRITERIA (3 times or more)}

- Systems in place for assessing hazards and risks associated with products, processes, and transportation and distribution activities $(2.1,2.2,2.3)$

- $\quad$ Reviewing performance of contractors (4.2)

- $\quad$ Analysis of trends and performance against goals (4.4)

- $\quad$ Responsibility and accountability (3.1)

- Training programs for specific skills and competencies (3.2)

- Management setting a framework for review and establishing goals, objectives and targets (1.4)

- $\quad$ Processes for reviewing appropriate regulations (2.5)

- $\quad$ Documented procedures to ensure safe operation (3.5)

- $\quad$ Management reflects commitment (1.7)

B. SPECIFIC MSV๑ ATTRIBUTES MISSING IN ISMSV CRITERIA

- Stakeholder/Public Involvement/Openness $(1.3,2.8,3.3,4.6,5.2)$

- $\quad$ Performance Management System that recognizes excellence (5.4)

- $\quad$ Benchmarking (5.3)

C. GENERAL MSV@ ATTRIBUTE CATEGORIES OF LESS FREQUENT MATCH TO ISMSV CRITERIA

- $\quad$ Policy and Leadership (1.1 - 1.8)

- $\quad$ Management Review and Reporting (5.1 - 5.4)

NOTE: Numbers in parentheses refer to specific MSV ${ }^{\infty}$ Attributes (Refer to Attachment B) 


\section{ISMSV PHASE II CRAD OBJECTIVES AND CRITERIA}

\section{BACKGROUND}

The following set of criteria and review approach documents (CRADs) provide a template for developing a tailored approach for conducting a Phase II ISMS verification of the implementation of ISMS within a facility or activity. The CRADS have been developed to provide a tool to enable the verification team to tailor a review based on evaluating the five functions of ISMS as implemented at the facility or activity. They support the expectations and attributes of ISMS described in Volume I, Chapter III of the ISMS Guide, DOE G 450.4-1.

All CRADs apply to each facility or activity to be reviewed. The Phase I ISMS verification report should be carefully reviewed prior to preparing the Phase II ISMS CRADs to ensure the recommended areas from the Phase I verification are included in the Phase II review. Team composition and review duration should be tailored to the specific facility or activity. Experience has shown that to successfully conduct a Phase II verification at a nuclear facility requires a team of 6-8 personnel and requires one week. A second week following the on site verification is generally required to analyze the results and write the report.

Each CRAD objective includes a reference to the specific ISMS Core Expectation (CE) it addresses. The referenced CE as delineated in DOE G 450.4-1, ISMS Guide, and Appendix 1 of this Handbook is included in parenthesis after the statement of the objective.

The CRADs have been divided and numbered to support a review that has Functional Areas of Hazard Identification and Standard Selection (HAZ), Management (MG), Operations (OP), Subject Matter Experts (SME), and Department of Energy Implementation (DOE).

In preparation of the tailored CRADs for the DOE review, the applicable DOE FRAM/FRA documents should be reviewed to determine the extent of the review approaches.

\section{DOE ISMS IMPLEMENTATION}

\section{OBJECTIVE}

DOE 1 DOE ISMS procedures and mechanisms should ensure that work is formally and appropriately authorized and performed safely. DOE line managers should be involved in the review of safety issues and concerns and should have an active role in authorizing and approving work and operations. (CE II-7) 


\section{CRITERIA:}

DOE 1.1 DOE procedures and/or mechanisms are in place that establish a process for confirming readiness and authorizing operations. (FRAM 9.5.1 and 9.5.2)

DOE 1.2 DOE procedures and/or mechanisms ensure that the safety management system is properly implemented and line management oversight of the contractor's worker, public, environment, and facility protection programs is performed. (FRAM 9.5.2)

DOE 1.3 DOE procedures and/or mechanisms require day-to-day operational oversight of contractor activities through Facility Representatives. (FRAM 9.5.2)

DOE 1.4 DOE procedures and/or mechanisms ensure the implementation of quality assurance programs and ensure that contractors implement quality assurance programs. (FRAM 9.5.3)

\section{OBJECTIVE}

DOE 2 DOE ISMS procedures and mechanisms ensure that hazards are analyzed, controls are developed, and that feedback and improvement programs are in place and effective. DOE line managers are using these processes effectively, consistent with FRAM and FRA requirements. (CE II-8)

\section{CRITERIA:}

DOE 2.1 DOE processes and/or mechanisms are in place to ensure that the contractor's hazard analysis covers the hazards associated with the work and is sufficient for selecting standards. (FRAM 9.3.1)

DOE 2.2 DOE procedures and/or mechanisms are in place in which DOE directs the contractor to propose facility or activity-specific standards tailored to the work and the hazards. DOE procedures require that appropriate safety requirements in necessary functional areas are included in contracts. (FRAM 9.4.1)

DOE 2.3 DOE procedures and/or mechanisms are in place that direct DOE line manager oversight to ensure that implementation of hazards mitigation programs and controls are established. (FRAM 9.4.2)

DOE 2.4 DOE procedures and/or mechanisms are in place that direct the preparation of the authorization basis documentation and oversee the implementation by the contractor. Procedures for development, review, approval, maintenance, and utilization of Authorization Agreements are implemented. (FRAM 9.4.3)

DOE 2.5 DOE procedures and/or mechanisms require that contractors develop a lessonslearned program and monitor its implementation. A process is established for reviewing occurrence reports and approving proposed corrective action reports. A DOE process is established and effectively implemented to continuously improve efficiency and quality of 
operations. Corrective actions are developed, implemented, and tracked in order to profit from prior experience and the lessons learned. DOE provides effective line oversight of the contractor's self-assessment programs. (FRAM 9.6.2)

\section{HAZARD IDENTIFICATION AND STANDARD SELECTION (HAZ)}

\section{NOTE}

The primary focus of this section of the review is the identification of hazards and development, review, and approval of Authorization Basis documentation at the facility level. Controls for individual work items or activities will be evaluated by the Operations and Subject Matter Expert functional area.

\section{OBJECTIVE}

HAZ 1 The full spectrum of hazards associated with the Scope of Work is identified, analyzed, and categorized. Those individuals responsible for the analysis of the environmental, health and safety, and worker protection hazards work closely with those personnel assigned to analyze the processes. (CE II-2)

\section{CRITERIA:}

HAZ 1.1 Procedures and/or mechanisms are in place and utilized by personnel to ensure hazards associated with the work throughout the facility have been identified and analyzed. The resulting documentation is defined, complete, and meets DOE expectations. The execution of these mechanisms ensure personnel responsible for the analysis of environmental, health and safety concerns work closely with those assigned to analyze the hazards for the facility or activity. These mechanisms ensure direction and approval from line management and integration of the requirements.

HAZ 1.2 Procedures and/or mechanisms are in place and utilized by personnel that describe the roles and responsibilities of those personnel who identify and analyze the hazards of the scope of work. Personnel assigned to accomplish those roles are competent to execute those responsibilities.

\section{OBJECTIVE}

HAZ 2 A process has been established and is utilized to develop controls that mitigate the identified hazards present within a facility or activity. The set of controls ensure adequate protection of the public, worker, and the environment and ase established as agreed upon by DOE. (CE II-3)

\section{CRITERIA:}

HAZ 2.1 Procedures and/or mechanisms are in place to develop, review, approve and maintain current all elements of the facility Authorization Basis Documentation.

HAZ 2.2 Procedures and/or mechanisms that require line managers to identify and implement appropriate controls for mitigation of the hazards present within the facility or 
activity are in place and utilized by personnel. These procedures/mechanisms reflect the set of safety requirements agreed to by DOE.

HAZ 2.3 Standards and requirements are appropriately tailored to the hazards.

HAZ 2.4 Procedures and/or mechanisms are in place to develop, maintain, and utilize Authorization Agreements.

HAZ 2.5 Procedures and/or mechanisms are in place to effectively and accurately implement all aspects of the Authorization Basis.

\section{MANAGEMENT (MG)}

\section{OBJECTIVE}

MG 1 A process has been established and is utilized to identify and prioritize specific mission discrete tasks, mission process operations, modifications and work items. (CE II-1)

\section{CRITERIA:}

MG 1.1 Procedures and/or mechanisms that require line management to identify and prioritize mission-related tasks and processes, modifications, and work items are in place and utilized by personnel.

MG 1.2 Procedures and/or mechanisms are in place and utilized by personnel that define the roles and responsibilities for the identification and prioritization of mission-related tasks and processes, facility or process modification, and other related work items. Personnel assigned to the roles are competent to execute these responsibilities.

MG 1.3 Procedures and/or mechanisms are in place and utilized by personnel that ensure identified work (i.e., mission-related tasks and process, processes or facility modification, maintenance work, etc.) can be accomplished within the standards and requirements identified for the facility.

\section{OBJECTIVE}

MG 2 A process has been established that ensures that mechanisms are in place to ensure continuous improvements are implemented through an assessment and feedback process, which functions at each level of work and at every stage in the work process. (CE II-5)

\section{CRITERIA:}

MG 2.1 Procedures and/or mechanisms are in place and utilized by personnel to collect feedback information such as self assessment, monitoring against performance objectives, occurrence reporting, and routine observation. Personnel assigned those roles are competent to execute those responsibilities. 
MG 2.2 Procedures are in place that develop feedback and improvement information opportunities at the site and facility levels as well as the individual maintenance or activity level. The information that is developed at the individual maintenance or activity level is utilized to provide feedback and improvement during future similar or related activities.

MG 2.3 Procedures and/or mechanisms are in place and utilized by managers to identify improvement opportunities. Evaluation and analysis mechanisms should include processes for translating operational information into improvement processes and appropriate lessons learned.

MG 2.4 Procedures and/or mechanisms are in place and utilized by managers to consider and resolve recommendations for improvement, including worker suggestions.

MG 2.5 Procedures and/or mechanisms are in place, which include a process for oversight that ensures that regulatory compliance is maintained.

\section{OBJECTIVE}

MG 3 Clear and unambiguous roles and responsibilities are defined and maintained at all levels within the facility or activity. Managers at all levels demonstrate a commitment to ISMS through policies, procedures, and their participation in the process. Facility or activity line managers are responsible and accountable for safety. Facility or activity personnel are competent commensurate with their responsibility for safety. (CE II-6)

\section{CRITERIA:}

MG 3.1 Procedures and/or mechanisms are in place that define clear roles and responsibilities within the facility or activity to ensure that safety is maintained at all levels.

MG 3.2 Facility or activity procedures specify that line management is responsible for safety.

MG 3.3 Procedures and/or mechanisms are in place that ensure that personnel who supervise work have competence commensurate with their responsibilities.

MG 3.4 Procedures and/or mechanisms are in place that ensure that personnel performing work are competent to safely perform their work assignments.

\section{OPERATIONS (OP)}

\section{OBJECTIVE}

OP 1 A process has been established and is utilized to effectively plan, authorize and execute the identified work for the facility or activity. (CE II-4) 


\section{CRITERIA:}

OP 1.1 Procedures and/or mechanisms are in place to ensure that work planning at the individual maintenance or activity level fully analyzes hazards and develops appropriate controls.

OP 1.2 Procedures and/or mechanisms are in place which ensure that there is a process used to confirm that the facility or activity and the operational work force are in an adequate state of readiness prior to authorizing the performance of the work.

OP 1.3 Procedures and/or mechanisms are in place which ensure that there is a process used to gain authorization to conduct operations.

OP 1.4 Procedures and/or mechanisms are in place which ensure that safety requirements are integrated into work performance.

OP 1.5 Procedures and/or mechanisms are in place which ensure that adequate performance measures and indicators, including safety performance measures are established for the work.

OP 1.6 Workers actively participate in the work planning process.

\section{SUBJECT MATTER EXPERT INTERACTIONS}

The following CRAD should be adapted as required and utilized by subject matter experts (SME) to assess whether the core functions and guiding principles of ISMS are met for the control of work within the specified discipline. Specific disciplines that have proven useful in past verifications include:

- Criticality Safety

- Fire Protection

- Industrial Hygiene and Safety

- Radiation Protection

- Security

- Training and Qualification

- Maintenance and Work Control

- Quality Assurance

- Configuration Management

- Environmental Compliance (including pollution prevention/waste minimization)

The evaluation of the maintenance and work control should be considered in every verification since this discipline normally demonstrates the essence of safely conducting work. 


\section{SUBJECT MATTER EXPERTS}

\section{OBJECTIVE}

SME 1 Within the individual subject area the planning of work includes analysis of hazards and development and specification of necessary controls. There is an adequate process for the authorization and control of work and a process for identifying opportunities for feedback and continuous improvement. Within the individual subject area, line managers are responsible for safety; clear roles and responsibilities have been established; and there is a satisfactory level of competence. (CE II-2, CE II-3, CE II-4, CE II-5, CE II-6)

\section{CRITERIA:}

SME 1.1 Procedures and/or mechanisms for the individual subject area require adequate planning of individual work items to ensure that hazards are analyzed and controls are identified.

SME 1.2 Procedures and/or mechanisms for the individual subject area contain clear roles and responsibilities. The individual subject area is effectively integrated with line support managers to ensure that line managers are responsible for safety.

SME 1.3 Procedures and/or mechanisms for the individual subject area require controls to be implemented and readiness to be confirmed prior to performing work.

SME 1.4 Procedures and/or mechanisms for the individual subject area require that personnel who are assigned to the subject area have a satisfactory level of competence.

SME 1.5 Procedures and/or mechanisms for the individual subject area require that within the subject area feedback and continuous improvement results. 


\section{MANAGEMENT SYSTEM VERIFICATION ATTRIBUTES}

\section{BACKGROUND}

Member companies of the Chemical Manufacturers Association are committed to support a continuing effort to improve the industry's responsible management of chemicals. They pledge to manage their businesses according to the Guiding Principles of Responsible Care, placing a high priority on the protection of the environment, the health and safety of their employees and the public, and the implementation of the Responsible Care management practices. To do so effectively their environmental, health and safety, and Responsible Care activities must be conducted within a structured system that is integrated with their overall management activity. The core elements of a Responsible Care management system are described below.

\section{POLICY AND LEADERSHIP}

This management element addresses the leadership exhibited by senior management in setting clear policy and guidelines for performance, and for enhancing the value of the Responsible Care ethic within the organization.

\section{$\underline{\text { Attributes }}$}

Senior management demonstrates leadership and commitment for their organization (company, plant or business unit) by active participation in the creation and implementation of a clear and visible policy that:

1.1 involves a demonstration of a personal commitment and dedication to Responsible Care;

1.2 is relevant to the nature and scale of the organization's products and processes;

1.3 fosters openness in dealing with stakeholders and takes into account public and employee inputs;

1.4 sets a framework for reviewing and establishing Responsible Care and environmental, health, and safety goals, objectives, and targets;

1.5 includes a commitment to continual improvement of the management of chemicals;

1.6 includes a commitment to comply with relevant legislation and regulations; 
1.7 reflects the company's commitment to the Guiding Principles of Responsible Care; and

1.8 is documented, maintained and communicated to employees.

\section{PLANNING}

This management element addresses; 1) the identification and assessment of relevant regulations and industry standards, 2) the evaluation of product, process and distribution risks, 3) the identification and assessment of employee and community concerns about the organization's environmental, health and safety performance, and 4) setting priorities and goals for performance improvement.

\section{Attributes}

The organization demonstrates appropriate planning by:

2.1 having systems in place for the assessment of hazards and risks associated with their products, including the integrating the risk evaluation process into the research and development of new products, or changes to existing products,

2.2 having systems in place for the assessment of hazards and risks associated with their processes, including the integrating the risk evaluation process into the research and development of new processes, or changes to existing processes,

2.3 having a system in place for the assessment of hazards and risks associated with transportation and distribution activities that includes impact on the environment, personnel and communities,

2.4 creating and maintaining a database for product information related to environmental, health and safety risks,

2.5 having processes in place for the systematic review of all environmental, health and safety related regulations, and their interpretations, that are relevant to the organization's activities,

2.6 maintaining documented Responsible Care goals, objectives, and targets which have clear means, time frames, and responsibilities for accomplishment,

2.7 having a system in place for the identification of needs and allocation of resources to implement performance improvements, and

2.8 having processes in place to assess community and employee concerns about the organization's activities. 


\section{IMPLEMENTATION, OPERATION AND ACCOUNTABILITY}

This management element addresses the achievement of objectives and policy expectations. It also covers the preparation and competence of employees to carry out their tasks, and documentation that is critical to the execution of those tasks.

\section{$\underline{\text { Attributes }}$}

The organization demonstrates that implementation, operation and accountability are part of their management system by the existence of:

3.1 a clear definition of responsibility and accountability for the execution of Responsible Care tasks;

3.2 training programs that include task specific skills and competencies, and awareness of regulatory requirements appropriate to the task;

3.3 a process for communication, outreach, and dialogue with stakeholders of relevant risks and impacts of the organization's activities to human health and the environment, and plans for improving the organization's Responsible Care management system;

3.4 employee involvement in the development, communication and execution of Responsible Care programs;

3.5 documented procedures to ensure safe operations for all processes, process changes and maintenance;

3.6 written site emergency response plans with appropriate considerations of communications and community recovery needs;

3.7 participation in the development of community emergency preparedness planning;

3.8 a documented process for responding to chemical transportation incidents;

3.9 programs to provide appropriate guidance, information and training requirements to carriers, distributors, customers, and contractors on the risks and hazards of the organization's products and processes, and for receiving guidance and information from suppliers on goods and services used by the organization;

3.10 processes for the qualification and selection of suppliers, carriers, distributors and contractors that place priority on environmental, health, and safety performance; and

3.11 emissions reduction, pollution prevention, and ground water protection programs. 


\section{PERFORMANCE MEASUREMENT AND CORRECTIVE ACTION}

This management element deals with the use of performance indicators, performance reviews, accident and incident investigation, compliance audits, data records, and taking or recommending corrective actions.

\section{Attributes}

The organization demonstrates the use of performance measurement and corrective action by having processes in place for:

4.1 the tracking of emissions and releases, accidents and injuries, process incidents, nearhits, and distribution incidents;

4.2 reviewing the performance of all carriers, suppliers, distributors, customers and contractors;

4.3 the investigation of accidents and incidents that get at the root causes of the occurrence and develop recommendations for prevention or corrective action;

4.4 the maintenance of sufficient data files to enable analysis of trends and performance against goals;

4.5 the audit or review of compliance with regulations and company procedures; and

4.6 the measurement of the effectiveness of its communications programs with its stakeholders.

\section{MANAGEMENT REVIEW AND REPORTING}

This management element addresses the manner in which the organization reports its performance to its stakeholders and senior management, and how the organization and senior management reviews that performance relative to goals and makes appropriate changes in goals, policies or priorities.

Attributes

Management Review and Reporting is characterized by evidence of:

5.1 periodic reviews of the organization's objectives and policies for relevance with consideration of products and processes, the expectations of stakeholders, and the performance versus goals and policies;

5.2 reporting mechanisms to stakeholders, employees and communities on the organization's Responsible Care results; 
5.3 benchmarking of Responsible Care management systems against other organizations; and,

5.4 a performance management system for employees that recognizes environmental, health, safety, and Responsible Care excellence. 
PANEL PARTICIPANTS

For the PFP ISMS Verification

Enhancement Review

1. RL UPPER MANAGEMENT PANEL

- Pete Knollmeyer

- Larry Romine

- Don Seaborg

- Shiv Seth

- Ben Burton

2. PFP UPPER MANAGEMENT PANEL

- Rich Redekopp

- Les Reed

- Paul Roege

3. PFP MIDDLE MANAGEMENT PANEL

- Bobby Gray

- Don McBride

- Liz Curfman

- Shirley Zeller

4. PFP WORKERS PANEL

- Dave Mitzlaff

- Ley Temple

- Anthony Hays

5. FDH UPPER MANAGEMENT PANEL

- Jerry Martin

- Andrea Hopkins

- Jon Geisbush

- Fred Crawford 


\section{REVIEW PANEL INTERVIEW QUESTIONS}

\section{A. MANAGEMENT INVOLVEMENT AND ACCOUNTABILITY}

1. Describe how your organization is structured to implement Integrated Safety Management and YOUR role in it.

1a. For RL and for FDH: How do you assure contractor conformance/compliance?

(Worker) Describe how your role in the organization will support the implementation of Integrated Safety management.

2. How do YOU PERSONALLY demonstrate your commitment and dedication to Integrated Safety Management?

(Worker) Describe how safety is a part of your daily work activities.

3. Describe how your safety management policy incorporates your/employee input(s) and public inputs.

3a. How does the policy reflect management's commitment?

(Worker) What opportunities does management give you to comment on safety policies or processes?

4. Describe your process for identifying resources needed and staffing required for safety management implementation.

4a. How do you know whether the resources you've allocated are adequate?

4b. What is YOUR role in this process?

(Worker) How does your manager identify and/or provide resources for performing work safely?

5. How do you establish safety management goals, objectives, and targets?

5a. Describe how workers are involved in these processes. 
5b. How is "continual improvement" addressed in the goals, objectives, and targets?

5c. What is YOUR role in this process?

(Worker) Describe your involvement in establishing safety goals, objectives and targets.

6. Describe how training needs related to safety management are identified and addressed.

6a. What is YOUR role in this process?

6b. How is this being translated into conduct of operations?

(Worker) How are training needs identified for workers in the area of safety?

7. Describe the performance measures you use to determine the effectiveness of your safety management system.

7a. How do you as a manager or worker know if you are doing a good job?

7b. What is YOUR role in this measurement process?

(Worker) How are you involved in identifying and providing input to safety performance measures?

8. Describe how you assign accountability and responsibility for the implementation of your safety management system.

(Worker) Describe how you as a worker are held accountable and responsible for working safely.

9. How have you incorporated safety management performance in your employee performance management process?

(Worker) How is your line manager held accountable for his or her participation / involvement in insuring work is done safely?

10. Describe how you benchmark/compare lessons learned with your safety management efforts to:

(Worker) How does your manager share lessons learned regarding safety from other facilities? 


\section{B. STAKEHOLDER COMMUNICATION AND INVOLVEMENT}

11. Describe how safety management policies and activities are communicated INTERNALLY.

(Worker) How are safety policies and activities communicated to workers?

12. Describe how safety management policies and activities are communicated EXTERNALLY.

(Worker) How do you communicate safety-related accomplishments and lessons learned with your friends, family or citizens of the community?

13. Describe how the risks and impacts of PFP's operations are communicated to: a) workers; and, b) the community.

(Worker) How are the risks and impacts of PFP operations communicated to you?

14. Describe how emergency response / community preparedness needs related to safety management at the PFP facility level are identified, addressed, and communicated.

(Worker) How are you involved in identifying, addressing, and communicating emergency response / community preparedness needs related to safety at the PFP facility?

15. How do you identify and assess employee and community expectations and concerns, regarding safety management, on an ongoing basis?

(Worker) How do you communicate expectations and concerns regarding safety to management?

\section{OTHER}

16. How will you ensure that the Integrated Safety Management effort will be sustained and institutionalized as a way of doing business?

(Worker) What will you do to ensure that the Integrated Safety Management system works at your facility? 
17. Are there any barriers that may impede long-term commitment to and progress regarding safety management?

(Worker) Are there any barriers that may impede long-term commitment and progress regarding safety management? 


\section{EFFECTIVENESS SURVEY \\ for the \\ ISMS Verification Enhancement Review \\ of PFP}

\section{$\underline{\text { PART I }}$}

Please indicate your opinions on the effectiveness of the Enhancement Review, as a tool for focusing on management involvement, commitment, and accountability and stakeholder/worker information and involvement, in the context of Integrated Safety Management (ISM), using the rating scale provided below. YOUR ANSWERS WILL BE KEPT COMPLETELY CONFIDENTIAL - ONLY GENERAL SUMMARIES OF MAJOR THEMES WILL BE PREPARED.

Effectiveness Rating Scale:

1

Not at all effective
2

Slightly

effective
3

Somewhat

effective
4

Moderately effective
5

Extremely

effective

Effectiveness of the Panel-to-Panel Dialogue Approach in Focusing on the Following Areas of Management System Performance Related to ISM:

Effectiveness:

1. Establishment of clear roles and responsibilities.

2. Senior management direction and leadership.

3. Strategic prioritization of resources.

4. Individual manager accountability.

5. Relevance of performance measures.

6. Relevance of goals and objectives.

7. Individual worker/employee accountability.

8. Internal communication of policies and activities.

9. External communication of policies and activities.

10. Overall sustainability of ISM. $\begin{array}{lllll}1 & 2 & 3 & 4 & 5\end{array}$

$\begin{array}{lllll}1 & 2 & 3 & 4 & 5\end{array}$

$\begin{array}{lllll}1 & 2 & 3 & 4 & 5\end{array}$

$\begin{array}{lllll}1 & 2 & 3 & 4 & 5\end{array}$

$\begin{array}{lllll}1 & 2 & 3 & 4 & 5\end{array}$

$\begin{array}{lllll}1 & 2 & 3 & 4 & 5\end{array}$

$\begin{array}{lllll}1 & 2 & 3 & 4 & 5\end{array}$

$\begin{array}{lllll}1 & 2 & 3 & 4 & 5\end{array}$

$\begin{array}{lllll}1 & 2 & 3 & 4 & 5\end{array}$

$\begin{array}{lllll}1 & 2 & 3 & 4 & 5\end{array}$ 


\section{$\underline{\text { PART II }}$}

In this section, please provide qualitative, narrative responses to the following questions:

1. Did this review help to gauge overall management commitment related to the ISM? Please explain.

2. Was there value to having a worker as part of the review team? Please explain.

3. Was there value to having a member of the public as part of the review team? Please explain.

4. Was there value to having a panel-to-panel dialogue versus a one-on-one discussion and/or presentation followed by questions? Please explain.

5. Do you see any value for this type of a review to provide a periodic assessment of ISM status?

6. Other comments? 


\section{PARTICIPANT EVALUATIONS - PART I RESULTS}

Code:

Panel A - RL UPPER MANAGEMENT

Panel B - PFP UPPER MANAGEMENT

Panel C - PFP MID-MANAGEMENT

Panel D - PFP WORKERS

Panel E - FDH UPPER MANAGEMENT

Effectiveness Rating Scale:

1

Not at all

effective
2

Slightly

effective
3

Somewhat

effective
4

Moderately effective
5

Extremely

effective

Effectiveness of Panel-to-Panel Dialogue Approach in Focusing on the Following Areas of Management System Performance Related to the ISM:

1. Establishment of clear roles and responsibilities.

\begin{tabular}{|l|c|c|c|c|c|c|}
\hline Rating & Panel A & Panel B & Panel C & Panel D & Panel E & TOTALS \\
\hline 1 & & & & & 1 & 1 \\
\hline 2 & & & 1 & & & 1 \\
\hline 3 & & & & 1 & 1 & 2 \\
\hline 4 & 4 & 2 & 2 & 1 & 2 & 1 \\
\hline 5 & 1 & 1 & 1 & 1 & & 4 \\
\hline
\end{tabular}

AVERAGE: 3.84 
2. Senior management direction and leadership.

\begin{tabular}{|l|c|c|c|c|c|c|}
\hline Rating & Panel A & Panel B & Panel C & Panel D & Panel E & TOTALS \\
\hline 1 & & & & & & 2 \\
\hline 2 & & 1 & 1 & & & 2 \\
\hline 3 & & & & 3 & & 3 \\
\hline 4 & 4 & 2 & & & 4 & 10 \\
\hline 5 & 1 & & 3 & & & 4 \\
\hline
\end{tabular}

\section{AVERAGE: 3.84}

3. Strategic prioritization of resources.

\begin{tabular}{|l|c|c|c|c|c|c|}
\hline Rating & Panel A & Panel B & Panel C & Panel D & Panel E & TOTALS \\
\hline 1 & & & & & & 2 \\
\hline 2 & & 1 & & & 1 & 2 \\
\hline 3 & 2 & & 3 & 3 & 3 & 11 \\
\hline 4 & 1 & 1 & 1 & & & 3 \\
\hline 5 & 2 & 1 & & & & 3 \\
\hline
\end{tabular}

AVERAGE: 3.36

4. Individual manager accountability.

\begin{tabular}{|l|c|c|c|c|c|c|}
\hline Rating & Panel A & Panel B & Panel C & Panel D & Panel E & TOTALS \\
\hline 1 & & & & & & 2 \\
\hline 2 & & & 1 & & 1 & 2 \\
\hline 3 & 2 & 1 & 1 & 1 & 2 & 7 \\
\hline 4 & 1 & 2 & 1 & 1 & 1 & 6 \\
\hline 5 & 2 & & 1 & 1 & & 4 \\
\hline
\end{tabular}

AVERAGE: 3.63 
5. Relevance of performance measures.

\begin{tabular}{|l|c|c|c|c|c|c|}
\hline Rating & Panel A & Panel B & Panel C & Panel D & Panel E & TOTALS \\
\hline 1 & & & & & & \\
\hline 2 & & 1 & & & 1 & 2 \\
\hline 3 & 1 & 1 & 1 & 2 & 1 & 6 \\
\hline 4 & 2 & 1 & 2 & 1 & 2 & 8 \\
\hline 5 & 2 & & 1 & & & 3 \\
\hline
\end{tabular}

AVERAGE: 3.63

6. Relevance of goals and objectives.

\begin{tabular}{|l|c|c|c|c|c|c|}
\hline Rating & Panel A & Panel B & Panel C & Panel D & Panel E & TOTALS \\
\hline 1 & & & & & & \\
\hline 2 & & & & & & 1 \\
\hline 3 & 1 & 1 & 1 & 2 & 6 \\
\hline 4 & 2 & 1 & 2 & 1 & 2 & 8 \\
\hline 5 & 2 & 1 & 1 & & 1 & 5 \\
\hline
\end{tabular}

AVERAGE: 3.94

7. Individual worker/employee accountability.

\begin{tabular}{|l|c|c|c|c|c|c|}
\hline Rating & Panel A & Panel B & Panel C & Panel D & Panel E & TOTALS \\
\hline 1 & & & & & 1 & 1 \\
\hline 2 & & & & & & 1 \\
\hline 3 & 2 & 1 & 1 & & 1 & 5 \\
\hline 4 & & 1 & 1 & 3 & 2 & 7 \\
\hline 5 & 3 & 1 & 2 & & & 6 \\
\hline
\end{tabular}

AVERAGE: 3.89 
8. Internal communication of policies and activities.

\begin{tabular}{|l|c|c|c|c|c|c|}
\hline Rating & Panel A & Panel B & Panel C & Panel D & Panel E & TOTALS \\
\hline 1 & & & & & & 1 \\
\hline 2 & & & 1 & & & 1 \\
\hline 3 & 1 & & 1 & 2 & & 4 \\
\hline 4 & 3 & 3 & 1 & 1 & 3 & 11 \\
\hline 5 & 1 & & 1 & & 1 & 3 \\
\hline
\end{tabular}

\section{AVERAGE: $\mathbf{3 . 8 4}$}

9. External communication of policies and activities.

\begin{tabular}{|l|c|c|c|c|c|c|}
\hline Rating & Panel A & Panel B & Panel C & Panel D & Panel E & TOTALLS \\
\hline 1 & & & & & & 2 \\
\hline 2 & 1 & & 1 & & & 2 \\
\hline 3 & 1 & 1 & 1 & 1 & 1 & 5 \\
\hline 4 & 2 & 2 & 2 & 2 & 2 & $\frac{10}{2}$ \\
\hline 5 & 1 & & & & 1 & 2 \\
\hline
\end{tabular}

AVERAGE: 3.63

10. Overall sustainability of ISM.

\begin{tabular}{|l|c|c|c|c|c|c|}
\hline Rating & Panel A & Panel B & Panel C & Panel D & Panel E & TOTALS \\
\hline 1 & & & & & & 1 \\
\hline 2 & & & 1 & & & 1 \\
\hline 3 & 2 & 1 & & & 1 & 4 \\
\hline 4 & 1 & 1 & & 3 & 2 & 7 \\
\hline 5 & 2 & 1 & 3 & & 1 & 7 \\
\hline
\end{tabular}

AVERAGE: 4.05 


\section{PARTICIPANT EVALUATIONS - PART II RESULTS}

Code:

Panel A - RL Upper Management

Panel B - PFP Upper Management

Panel C - PFP Middle Management

Panel D - PFP Workers

Panel E - FDH/BWHC Upper Management

1. DID THIS REVIEW HELP TO GAUGE OVERALL MANAGEMENT COMMITMENT RELATED TO THE ISM? PLEASE EXPLAIN.

\section{$\underline{\text { PANEL A }}$}

- Yes, most questions were directed directly or indirectly towards this objective.

- Yes, this provided insight to expectations and perceptions.

- Yes, but only when combined with the results of the remaining panels.

- Management understands the concept of ISM, but need to ensure the awareness of ISM in the forefront.

- Yes, stimulated good thought on strengths and weaknesses.

\section{$\underline{\text { PANEL B }}$}

- Yes, through specific questions.

- Yes, the personal interview/panel discussion offered the opportunity to see personal commitment and response to questions; it also allowed for panel member responses to build upon each other.

- No, we are contractually required to implement ISM - any good group would be able to be prepared for the review and put their best foot forward.

\section{$\underline{\text { PANEL C }}$}

- Yes, pointed questions regarding management commitment.

- Yes, the management representatives were given good opportunity to demonstrate, through examples, commitment to ISMS.

- Yes, I like the panel format, lots of opportunity to discuss responses and clarify questions.

- I think this review demonstrated the strong management commitment at PFP. 


\section{$\underline{\text { PANEL D }}$}

- Yes, management is behind this.

- Yes, this needs to be given to as many people as possible.

\section{PANELE}

- Yes, it puts management commitment to ISM as a top priority.

- Did not especially gauge the commitment - more the communication of the commitment.

- Difficult to evaluate from my standpoint. Really a question for the panel.

- I do believe so. Management commitment was established long ago. I think the review brought this out.

2. WAS THERE VALUE TO HAVING A WORKER AS PART OF THE REVIEW TEAM? PLEASE EXPLAIN.

\section{PANEL A}

- Extremely valuable - especially for raising issues important to worker (e.g., criticality safety at PFP, hazards analysis, training of employees.)

- Yes, great perspective on worker point of view; i.e., training importance.

- Yes!! Excellent idea.

- Yes, they MUST be involved to the point of "buy in" or else the program is unsuccessful.

- Yes, kept focus on worker involvement.

\section{$\underline{\text { PANEL B }}$}

- Yes, it allows for a different perspective and maintains the focus that many levels of programs are involved.

- Yes, the most important and worthwhile aspect of ISM is at the working level. The worker involvement helps the panel keep one foot on the ground.

- Yes, understood discussions related in plant work activities.

\section{PANELC}

- Yes, able to keep conversation focused on worker involvement.

- Yes, had a clear perspective without political inhibitions.

- Yes, it's a key viewpoint for understanding application of ISMS in the field where it matters. Also increases credibility of the panel.

- Having a worker involved demonstrated the ISMS principles.

\section{$\underline{\text { PANEL D }}$}

- Yes, it gave a worker view. 
- Yes, because these are the largest quantity of people that are involved with work safety themselves.

\section{PANEL E}

- Very much so. The worker is a key player in ISM and added value to this review.

- Yes, all perspectives, especially the workers' perspective, are important. The worker's perspective is key in terms of feedback to the system on the basic question of what is effective and what is not effective in the field.

- Yes, the professional work force is the key to safety.

- Yes, he clarified, amplified, and put some personal touch on the topics. I would have expected some pointed questions in areas he wants more support.

3. WAS THERE VALUE TO HAVING A MEMBER OF THE PUBLIC AS PART OF THE REVIEW TEAM? PLEASE EXPLAIN.

\section{PANEL A}

- Extremely valuable - in raising community related issues (e.g., emergency response capabilities, preparation and planning of emergency response to changing hazards, information availability to public, etc.)

- Yes, provides good perspective of external views.

- Yes!! Adds credibility and a valuable perspective we don't normally see.

- Yes, without their confidence in the program, we constantly reinvent the wheel.

- Yes, same as worker. Kept good focus on community involvement and education process.

\section{$\underline{\text { PANEL B }}$}

- Not a great deal from my perspective but probably significant from theirs.

- Yes, interesting perspective and feedback. We tend not to be very aware or conscious of public interaction.

- Neutral, the team member was easy to converse with - just viewed him as another team member.

\section{PANEL C}

- Neutral, questions were good but not sure they wouldn't have been the same from site participation. He didn't necessarily focus on external views.

- Not sure but made me aware of external stakeholder interest in implementation of ISMS.

- Probably yes, again, increases credibility of the panel, plus keeps panel participants cognizant of how the process might be viewed from outside.

- It was very effective to have a member of the public involved. All areas were represented on the review team. 


\section{PANEL D}

NOTE: The public participant was not able to participate in the worker panel.

\section{PANEL E}

- Yes, public involvement and public knowledge of our Hanford work and risks are fundamental.

- Yes, it reminded me that the public has a key interest in safety at Hanford. Sometimes I focus so much on the internal aspects I need to be reminded that the public needs to stay informed.

- Yes, to be able to involve the public as a member of an evaluation such as this is valuable to the facility and provides insight to the public as well.

- Yes, I think he shed some light on what the public expects through his questioning. However, I don't expect any changes as a result of his questions.

4. WAS THERE VALUE TO HAVING A PANEL-TO-PANEL DIALOGUE VERSUS A ONE-ONONE DISCUSSION AND/OR PRESENTATION FOLLOWED BY QUESTIONS? PLEASE EXPLAIN.

\section{PANEL A}

- Yes, because questions as well as responses can build upon each other and thereby improve the thrust of questions and the depth of responses.

- I thought the panel was better than one-on-one. This provides a more thorough discussion and fosters other thought and points of view.

- Yes, because I forget things that other panel members remembered and vice versa.

- Yes, this allows for understanding where the question/answer is going.

- Yes, comments by others led to added insight, comments and identification for areas to improve.

\section{$\underline{\text { PANEL B }}$}

- Yes, variety and change of pace.

- It is always easier to answer questions when you can build on another's thoughts.

\section{PANEL C}

- Yes, less intimidating. Also, it's easier to cover all aspects by feeding off each other - a true team approach.

- Yes, triggered discussion that might have otherwise gone by the wayside. 
- Yes, panelists (on both sides) can build on or clarify the responses or questions of others.

- I feel that the panel discussion was much more effective than the one-on-one interview process. I believe that the dialogue was very open and honest because of this approach.

\section{PANEL D}

- Yes, many different points of view.

\section{PANEL E}

- Panel-to-panel best approach since each member of the panel added to the group's knowledge.

- The panel-to-panel approach is more effective because of it's interactive nature. The less formal setting is conducive to more frank dialogue.

- Depends on the objective. I am not clear on what we were supposed to accomplish. It was valuable training for me to think about the questions.

- Little value. In particular at this point in time. We are in transition. The review was focused on PFP and there was only one person who really understood the PFP situation to the extent of being able to give first hand experience.

5. DO YOU SEE ANY VALUE FOR THIS TYPE OF A REVIEW TO PROVIDE A PERIODIC ASSESSMENT OF ISM STATUS?

\section{PANEL A}

- Yes, this would be a good approach. As a minimum, it would raise safety awareness periodically and bring to light emerging issues.

- Possibly, very good as an initial assessment.

- Yes, to gauge the progress and to potentially set up some parameters.

- Yes, good tool to force organization being assessed to look inward and outward with respect to ISM.

\section{$\underline{\text { PANEL B }}$}

- Yes, it is quick yet effective.

- Yes, we need to go through a thought-provoking process once in a while or we tend to think we're doing fine (on those areas we're thinking about).

- From a facility perspective, it does not help us. It takes time out of a busy schedule. From an oversight standpoint, it is an easy way to discuss a facility's ISM program. 


\section{$\underline{\text { PANEL C }}$}

- Possibly as a shorter follow-up review - with different mix of participation - i.e., manager, worker, team lead, etc.

- Yes, good experience to force us to self-evaluate our readiness.

- I believe the main value of ISM is in the field implementation, not the verification process. After verification is initially completed, a follow-up field observation of work planning and execution would seem more valuable.

- I feel that a periodic review would help keep the momentum going. Otherwise it will fall between the cracks until the next annual review.

\section{PANEL D}

- Yes, it allows people to view the work being done.

- Yes, if this is done periodically.

\section{PANELE}

- Yes, must make clear the objective and evaluate cost benefit. May be less costly ways of achieving objective.

- No, have the people go to the field and see if it is working.

6. OTHER COMMENTS?

\section{PANEL A}

- Panel did a great job.

\section{PANEL B}

- The panel discussion is useful as an element of the evaluation - other tools needed to provide a more complete picture (employee interviews, surveys, look at examples of performance indicators, etc.)

\section{$\underline{\text { PANEL C }}$}

- Good experience to force us to self-evaluate our readiness. 


\section{PANELE}

- For the questions asked, time was too short if you wanted to understand ISM and all we do at PFP that implements ISMS.

- We get too enamored with systems and managementese. We need to focus on making sure the work is done correctly - holding people accountable and keeping the bureaucracy simple. I am not opposed to the people only the process. 


\section{DISTRIBUTION SHEET}

To

Distribution

Project TitleMork Order

The Integrated Safety Management system Verification Enhancement Review of the Plutonium Finishing Plant

\section{Name}

\section{J. A. Goeckner}

S. L. Johnson

P. M. Knollmeyer

S. S. Seth

D. S. Shoop

Central Files

DOE Reading Room

$D P C$

Hanford Tech. Library
From

Page 1 of 1

Date $02 / 24 / 2000$

EDT No.

ECN No.

\begin{tabular}{c|c|c|c|}
$\begin{array}{c}\text { Text } \\
\text { With All } \\
\text { Attach. }\end{array}$ & Text Only & $\begin{array}{c}\text { Attach./ } \\
\text { Appendix } \\
\text { Only }\end{array}$ & $\begin{array}{c}\text { EDT/ECN } \\
\text { Only }\end{array}$ \\
\hline
\end{tabular}

